Tavares, P. H. - Flusser com Freud

\title{
Flusser com Freud: Tradução, Sujeito e Cultura
}

\author{
[Flusser with Freud: Translation, Subject and Culture]
}

\begin{abstract}
In the following article, we present Sigmund Freud and Vilém Flusser not only as two intellectuals who shared some biographical similarities, but also as two important thinkers of converging propositions. Both critically analyzed the human unease towards individual and cultural differences mediated by the symbolic, and both, each one on his way, tried to propose ways of dealing with the question by emphasizing the creative powers of language and translation to overcome the boundaries of resistance, intolerance and miscommunication. Therefore, we intended here to discuss the contribution to the understanding of each one of these writers and their ideas by proposing a crossed reading of their works.
\end{abstract}

Key-Words: Sigmund Freud; Vilém Flusser; Unease in the culture; Translation; subjectivity

Resumo: Neste artigo pretendemos apresentar Sigmund Freud e Vilém Flusser não somente como dois intelectuais que dividem certas peculiaridades biográficas, mas como dois importantes pensadores de proposições convergentes. Ambos analisaram criticamente o malestar humano face às diferenças individuais e culturais mediadas pelo simbólico e ambos, cada qual ao seu modo, procuraram apresentar maneiras de lidar com tal questão enfatizando as capacidades criativas da linguagem e da tradução em ultrapassar os limites das diferenças, da intolerância e do mal-entendido. Pretendemos, portanto, discutir aqui as contribuições para o entendimento de cada um destes escritores a partir de uma leitura cruzada de suas obras.

Palavras-Chave: Sigmund Freud; Vilém Flusser; Mal-estar na cultura; Tradução; subjetividade

Enquanto o nome de Sigmund Freud praticamente dispensa apresentações, Vilém Flusser estranhamente é ainda para muitos um desconhecido. No caso de Freud, talvez não seja exagero dizer se tratar do mais influente intelectual do século $\mathrm{XX}$ no que tange aos estudos sobre a subjetividade. Quanto a Flusser, porém, não somente sua

\footnotetext{
${ }^{1}$ Professor de Língua e Literatura Alemãs, DLM | FFLCH| USP. Doutor em Psicanálise e Psicopatologia (Université Paris VII). Autor de Freud \& Schnitzler (2007), Versões de Freud (2011) e Fausto e a Psicanálise (2012).Email: pht@usp.br

Pandaemonium, São Paulo, v. 17, n. 23, Jun. /2014, p. 223-239
} 
Tavares, P. H. - Flusser com Freud

posterioridade é histórica, mas também é muito mais recente a popularização de suas proposições entre os intelectuais no Brasil e no exterior, sobretudo, na Alemanha.

A verdade é que ambos, Flusser e Freud, dividem certas particularidades: judeus poliglotas, nasceram entre os tchecos e os austro-alemães e foram forçados a abandonar suas terras de origem para não sofrerem o trágico destino de tantos familiares seus: os campos de extermínio. Ambos são forçados a abandonar o espaço reclamado pelos ditos representantes de um povo, cuja língua foi para eles o mais fundamental meio de reflexão e expressão: a língua alemã. Viveram com intimidade o mal-estar e o desencontro do sujeito com uma língua e uma cultura específicas e, cada qual ao seu modo, procuraram lidar intelectualmente com esse aparente impasse através de uma escrita de proposições inovadoras e desafiantes.

Para tratar das questões da obra de Freud envolvendo os fenômenos da linguagem, tais como o estilo na escrita, as construções narrativas, as possibilidades de expressão e significação do sujeito, me fiz valer em pesquisas anteriores de semelhante aproximação de sua obra com outro Doppelgänger (duplo) seu: o escritor e dramaturgo Arthur Schnitzler. Ambos originariamente médicos, judeus, vienenses, assistentes de Theodor Meynert e interessados pelas afasias e pela histeria, foram praticamente coetâneos. No caso de Flusser face a Freud, esse paralelo poderia ser sugerido não como coincidência temporal, mas como uma "passagem de bastão" no tocante às reflexões sobre o irremediável mal-estar do sujeito, do "ser falante", na cultura e entre as fronteiras nacionais e intelectuais. Tal momento de passagem seria justamente o da Segunda Guerra Mundial, como o que marca o ocaso de um para a aurora do outro desses pensadores.

Seguindo tal cronologia, comecemos portanto, com Freud. Com a Anschluss promovida pelo Estado nazista em 12 de março de 1938, Freud escreve em seu diário, não em alemão, mas em latim: "Finis Austriae" (GAY 1999: 560). Já padecendo há anos as consequências do carcinoma, cujos sofrimentos o levarão ao recurso extremo da eutanásia um ano depois, Freud se vê forçado a abandonar Viena, migrando para Londres com sua família. Mesmo que lhe restassem poucos meses de vida, o abandono de suas terras de origem foi imprescindível para preservar a existência de sua família nuclear. Sua esposa e filhos foram assim preservados do destino que tiveram suas quatro irmãs.

Pandaemonium, São Paulo, v. 17, n. 23, Jun. /2014, p. 223-239 
Tavares, P. H. - Flusser com Freud

Na verdade, em seu Selbstdarstellung (Ensaio Autobiográfico), o fundador da Psicanálise já colocara esta condição de constante migração, que seu pertencimento étnico teria imposto às gerações anteriores de sua família:

Nasci dia 6 de maio de 1865 em Freiberg na Morávia, numa pequena cidadezinha da atual Tchecoslováquia. Meus pais eram judeus, assim como eu segui sendo judeu. De minha família paterna, creio poder dizer que por muito tempo viveram na região do Reno (em Colônia), que de lá fugiram para o leste em decorrência de uma perseguição aos judeus no século quatorze ou quinze, para finalmente, ao longo do século dezenove, retornarem da Lituânia através da Galícia para a Áustria alemã². (FREUd 1930: 34)

Janine Altounian, tradutora e ensaísta francesa, filha de sobreviventes do genocídio armênio, certamente amparada por sua própria história familiar, é quem nos aponta o quanto a questão do desterro em decorrência da perseguição étnica trará uma marca indelével ao pensamento freudiano. Altounian, afinal, além de ter escrito trabalhos importantes, tais como Ouvrez-moi seulement les chemins d'Arménie - Un génocide aux déserts de l'inconscient (1990); La Survivance - Traduire le trauma collectif, (2000), e L'intraduisible - Deuil, mémoire, transmission (2005), nos quais articula as ideias freudianas ao trauma do genocídio e da diáspora de seu povo, publicou também um importante livro a respeito de suas observações como tradutora da obra de Freud para o francês. Trata-se de L'Écriture de Freud - Traversée Traumatique et Traduction, no qual a autora fundamenta sua tese justamente a partir do recém-citado extrato do ensaio autobiográfico de Freud:

Freud criou e pensou a psicanálise num universo simbólico de signos do qual ele foi expulso por aqueles que, como é sabido, expulsaram suas irmãs do mundo dos vivos [...] Estas oito linhas iniciais da Autoapresentação (Selbstdarstellung) de Freud concentram em si mesmas, para seus antepassados, cinco locais de residência, dez topônimos, uma perseguição racial e/ou religiosa, duas migrações e rupturas, três experiências linguísticas para ele e um pertencimento identitário que questiona todas as evidências habitualmente atribuídas à origem (ALTOUNIOAN 2003: 23, tradução nossa).

\footnotetext{
2 "Ich bin am 6. Mai 1865 zu Freiberg in Mähren geboren, einem kleinen Städtchen der heutigen Tschechoslowakei. Meine Eltern waren Juden und ich bin Jude geblieben. Von meiner väterlichen Familien glaube ich zu wissen, dass sie lange Zeiten am Rhein (in Köln) gelebt hat, aus Anlass einer Judenverfolgung im vierzehnten oder fünfzehnten Jahrhundert nach dem Osten floh und im Laufe des neunzehnten Jahrhunderts die Rückwanderung von Litauen über Galizien nach dem deutschen Österreich antrat.".
}

Pandaemonium, São Paulo, v. 17, n. 23, Jun. /2014, p. 223-239 


\section{Tavares, P. H. - Flusser com Freud}

Seguindo a indicação da autora (2003: 24), podemos perceber, de fato, como o vocabulário metapsicológico de Freud é influenciado por estas forças de imposição do deslocamento forçado. Nos recentes estudos que fizemos sobre o vocabulário alemão de Freud e suas versões para outras línguas, pudemos verificar uma impressão muito semelhante à expressa por Altounian quanto a alguns dos mais centrais dos conceitos fundamentais da sua metapsicologia. São os casos de Trieb (pulsão), muito próximo do drive inglês, como a grande "força motriz" que se impõe ao psiquismo em sua condução. Da mesma forma, teríamos o termo da pulsão Drang (pressão, ímpeto, ânsia) e seu aparentado Verdrängung (recalque, repressão), cuja acepção corrente mais direta seria a de desalojamento. Na mesma trilha, Zwang, correntemente traduzido por obsessão ou compulsão, tem na sua acepção cotidiana os sentidos de "obrigação, pressão, violência” que se impõe a alguém (cf. IRMEN, 1988). Nessa trilha os exemplos seriam muitos: Verschiebung (deslocamento), Verwerfung (rejeição, repúdio), Übertragung (transferência, transdução), etc.

Quanto a Flusser, ele fez de seu desterro, da obrigação a uma vida errante, o ponto alto de seu pensamento. Como o célebre escritor Franz Kafka, ou como o poeta Rainer Maria Rilke, Flusser era um cidadão de Praga de expressão alemã. Praga era então uma cidade de três nações e duas (ou três) línguas quando lá nasceu o autor, em 1920. Seus antepassados haviam se fixado na capital da Boêmia havia séculos e, não sem conflitos, ali conviveram também por séculos esses tão distantes povos: os tchecos eslavos, os judeus e os austro-alemães. A tensa convivência entre nações tão distintas certamente em muito colaborou para que Praga se tornasse um centro tão importante para o desenvolvimento do saber e da cultura (cf. FINGER 2008).

Após a segunda guerra, porém, Praga se tornará uma cidade fantasma de dois dos seus três povos. Quem atualmente anda por suas encantadoras ruas percebe, afinal, a "ausência onipresente" dos judeus e dos alemães entre os tchecos hoje remanescentes, aqueles que dela fizeram a capital da República que leva o nome de sua nação. Freud, como vimos, nasceu na cidade a que os alemães e judeus chamavam de Freiberg, mas que os tchecos chamavam de Přibor, na Moravia, região que junto com a Boêmia compõe a atual República Tcheca.

No caso do tcheco Flusser, como ocorrera com Freud, a invasão nazista também forçou sua migração para a Inglaterra junto com a família de sua esposa. Entretanto, não 
Tavares, P. H. - Flusser com Freud

tardou para que as bombas começassem a cair sobre a capital britânica, fazendo com que Flusser tivesse que novamente se mudar, desta vez, porém, para outro continente. As opções eram China (Shangai), Panamá ou... Brasil. Ao aportar, maravilhado pelas luzes noturnas do Rio de Janeiro, após um ano e meio sem ver "o bulbo ardente de uma lâmpada" (FINGER 2008: 23), a sombra das terras abandonadas o reencontram. Ao colocar os pés nestas terras, recebe uma notícia que lhe retira o chão sob os pés, deixando-o bodenlos, vocábulo ao qual voltaremos. O pai, que insistira em permanecer em Praga, havia sido morto num campo de concentração. Do porto do Rio, Flusser segue diretamente a uma sinagoga para prestar a homenagem da oração kadish, em honra ao seu genitor (id.).

Com Freud aprendemos algo sobre a relação da morte do pai com o nascimento do homem. Para o criador da Psicanálise, amparado no mito de Édipo, o parricídio simbólico seria condição para a emancipação do sujeito, que deixa de ser um mero seguidor de outro para, de alguma forma, ser também um autor emancipado de sua singular existência. Se isso ocorre invariavelmente no plano simbólico, não é livre de conflitos e complicações quando temos a concomitância da perda física e violenta deste pai de fato, bem como a avassaladora morte ou perda de outro, do Vater-land (terra pai Pátria).

Freud e Flusser souberam aí se utilizar do autobiográfico como grande laboratório e campo de investigação para suas questões. Freud admite que o advento de sua obra mestra, a Traumdeutung (A Interpretação dos Sonhos), após a morte do pai está longe de ser uma coincidência. O psicanalista, aliás, esperou de 1899 até 1900 para publicá-la como o marco para um novo século, para um novo tempo. Não somos, afinal, filhos somente de nossos genitores e de nossa pátria, somos filhos de nosso tempo. Disso já sabiam os Gregos: o primeiro grande parricida foi ninguém menos que Zeus, o senhor do Olimpo ao matar seu pai, cujo nome era Kronos (Chronos - tempo), marcando com isso uma nova era.

As propostas revolucionárias de Freud com seu livro sobre os sonhos e o inconsciente fez com que seu biógrafo, o historiador Peter Gay, denominasse tal obra Freud: uma vida para nosso tempo (Freud: a life for our time), a partir da virada para o século XX (GAY 1999). Já Flusser, filho intelectual do mais tenebroso eclipse dos 


\section{Tavares, P. H. - Flusser com Freud}

últimos tempos, chamará de pós-história ${ }^{3}$ (Nachgeschichte) o tempo que vem depois de Auschwitz (1983). Quanto a Flusser, sua autobiografia foi também publicada no Brasil com um curioso título em língua alemã: Bodenlos (1992/2010). A sua não-tradução não parece ser aí algo inocente. Imaginamos o quão "desnorteado" ou de fato "sem chão", tradução literal do vocábulo, fica o leitor diante desta estranha/estrangeira palavra que pode ser entendida também como "sem-fundamento", "sem país".

Quer dizer, nossos pais existenciais são ao menos dois: somos filhos de nosso tempo e de nossa pátria, mas há aí um terceiro e crucial elemento engendrador: a língua. A grande polêmica em torno das teses freudianas sobre o papel crucial da sexualidade no desenvolvimento do psiquismo talvez tenha colocado em segundo plano o outro aspecto revolucionário de suas propostas: o papel fundamental da linguagem no psiquismo. A rigor, aliás, confundem-se facilmente os termos sexualidade (próprio à humanidade, ao ser falante) e genitalidade (presente nas mais diversas espécies). Para Freud, porém, o divisor de águas essencial do ser humano para os outros animais não seria tanto o nosso "bônus", ao termos ganhado a cultura através da linguagem. Seria, sobretudo, o "ônus" ao termos perdido o "saber" biológico, das programações instintuais. Isso quer dizer que nossos corpos, mediados pela linguagem, são atravessados pelo simbólico, o que nos faz ignorantes, inconscientes, de nossos próprios objetos e objetivos no mundo. Em suma: a linguagem que organiza e constrói os belíssimos castelos da cultura, lança à deriva o "tão dividido in-divíduo".

Não somos a imagem do perfeito criador esculpida em barro, tampouco a racional nata da criação ou da evolução, somos seres colocados em falta (não a do pecado, mas a da falha) a partir do advento da palavra que nos medeia a relação com a realidade e nos afasta das coisas em si ou dos "dados brutos", no linguajar flusseriano. A evolução e a conquista do fogo divino da ciência e da tecnologia nos fez carecas e neuróticos, o que segundo Freud nos convidaria a repensar a comum confusão entre evolução e progresso.

Já em Flusser a importância dada à linguagem e a comunicação é direta, central e inequívoca. Seu primeiro livro foi escrito no Brasil em português e recebeu o título Língua e Realidade quando publicado em 1963 pela Editora Herder. Flusser radicou-se

\footnotetext{
${ }^{3}$ Flusser utiliza o conceito de pós-história, sobretudo, para se referir ao momento em que as imagens técnicas triunfam em relação à escrita/escritura.
}

Pandaemonium, São Paulo, v. 17, n. 23, Jun. /2014, p. 223-239 
Tavares, P. H. - Flusser com Freud

em São Paulo, cidade na qual morou entre 1941 e 1972 e onde se deu o desenvolvimento de uma importante interlocução com nossos intelectuais, tais como Miguel Reale, Haroldo de Campos, Guimarães Rosa, entre outros. Colaborou com importantes jornais, tais como O Estado de São Paulo, e lecionou Filosofia na década de 1960 na Escola Politécnica da USP, antes de ser criada a atual FFLCH em 1972, para a qual não teria sido convidado por questões políticas, segundo alguns, ou devido a problemas burocráticos envolvendo a não-comprovação de títulos acadêmicos, segundo outras fontes. As questões políticas aí não seriam as já tão largamente debatidas perseguições aos intelectuais por parte da ditadura militar.

$\mathrm{Na}$ verdade, Flusser causava desconforto mesmo era entre os colegas docentes de filosofia, fossem estes defensores das tradicionais correntes aristotélicas, kantianas ou marxistas. Era um antiacadêmico por excelência, tendo afirmado em Zwiegespräche (Conversações), ao final de sua vida, portanto: "Todo pensamento sistemático está errado, todo sistema é uma violação. A realidade é emaranhada e por isso interessante. Todo pensamento cartesiano que cria ordem é fascista" (1990: 97).

Mas voltando ao primeiro livro de Flusser, Língua e Realidade, este foi muito mal recebido no meio filosófico brasileiro da época e taxado de ser uma ficção filosófica. Não tão distinta foi afinal a recepção dos escritos de Freud, chamados por Richard von Krafft-Ebing de "conto-de-fadas científico" (apud GAY 1999: 100). Anatol Rosenfeld, em sua resenha ao livro mencionado, é um tanto duro ao discordar das premissas ontológicas de Flusser, que fariam equivaler, por exemplo, as existências de um centauro (ser imaginário), um triangulo (ser ideal) e uma árvore (ser real). No entanto, Rosenfeld é bastante elogioso ao considerar o livro como "poético" (apud MARTINS 2011).

Eis aí um ponto fundamental. Era, aliás, também nos poetas/escritores criativos (Dichter), mais que nos filósofos ou cientistas, que Freud buscava os grandes aliados para a construção de seu saber. Como afirmara em Der Dichter und das Phantasieren (Escritores criativos e os devaneios) (1907):

Os escritores criativos são aliados muito valiosos, e seus testemunhos devem ser levado em alta conta, pois costumam conhecer toda uma vasta gama de coisas entre o céu e a terra com as quais a nossa "sabedoria escolar" (Schulweisheit) ainda não nos deixou sonhar. Estão bem adiante de nós, gente comum, no conhecimento do psiquismo, já que 
Tavares, P. H. - Flusser com Freud

se nutrem em fontes que ainda não tornamos acessíveis à ciência ${ }^{4}$ (FREUD 1907: 14 grifo nosso).

Tanto Flusser quanto Freud encontraram na Poética maiores possibilidades de lidar com o saber que procuravam desvendar do que na Ciência (primeiro caminho freudiano) ou na Filosofia (primeiro caminho flusseriano). Entre uma intencionalidade filosóficocientífica e um reconhecimento da capacidade criativo-poética da palavra, o meio-termo talvez nos leve a abordar muitos de seus escritos como mais próximos do gênero ensaio.

Ensaio, através do francês, vem afinal de tentativa (essai), de uma tentativa que admite suas limitações e convida a um gesto de concomitante modéstia e soberba. A modéstia é a de quem reconhece o quão ingênuo pode ser o projeto de um cientista ou filósofo que queira com seu conhecimento abarcar a existência e "traduzi-la", em linguagem; já a soberba estaria em ousar expandir os limites do dizível, fazendo a língua superar sua capacidade meramente descritiva da realidade. Nesse sentido, vale lembrar a grande divisa flusseriana "a poesia aumenta o território do pensável, mas não diminui o território do impensável” (apud BERNARDO 2007: 121).

Freud e Flusser estavam condenados à rejeição pelos colegas cientistas e filósofos, tendo que viver e pensar à margem da academia. Freud, médico, aponta na histeria a possibilidade de que não só o corpo pode ser adoecido, revolvido e tratado pela palavra, mas que é pela palavra que aprendemos a construir o olhar sobre o corpo. Com a Psicanálise aprende-se a se ressignificar a noção joaniana do verbo ( $\lambda$ ơóc) que faz corpo e vem habitar o mundo. Para tal concepção, de uma clínica da escuta de um “corpo de signos”, a medicina anátomo-patológica, a clínica do olhar sobre a carne, não tinha espaço. A clínica de Freud será a grande pioneira em reconhecer a "eficácia simbólica", abrindo o caminho para o pensamento estruturalista por vir. É ele quem resgata o encontro da narrativa com o conhecimento, encontro desfeito desde o abandono do discurso mítico em prol do filosófico. É a palavra o que está no cerne mesmo de seu método e objeto:

\footnotetext{
${ }^{4}$ Wertvolle Bundesgenossen sind die Dichter, und ihr Zeugnis ist hoch anzuschlagen, denn sie pflegen eine Menge von Dingen zwischen Himmel und Erde zu wissen, von denen sich unsere Schulweisheit noch nicht träumen lässt. In der Seelenkunde gar sind sie uns Alltagsmenschen weit voraus, weil sie aus Quellen schöpfen, welche wir noch nicht für die Wissenschaft erschlossen haben
}

Pandaemonium, São Paulo, v. 17, n. 23, Jun. /2014, p. 223-239 
Tavares, P. H. - Flusser com Freud

As palavras eram originalmente mágicas e mantêm ainda muito de seus antigos poderes mágicos. Pelas palavras pode se fazer alguém feliz ou levá-lo ao desespero, pelas palavras um professor transmite seu saber a um aluno, pelas palavras um orador arrebata a congregação de seus ouvintes e influencia seu julgamento e decisões. Palavras suscitam afeto e são, de modo geral, o meio de mútua influência entre os homens. Assim sendo, não desprezemos o uso das palavras na psicoterapia, e nos agradará ouvir as palavras trocadas entre o analista e seu paciente (FREUD 1916: 43). ${ }^{5}$

Se para Freud era necessário traduzir a língua do inconsciente ao consciente, a língua dos sintomas, à da associação-livre, no intuito de gerar uma superação no plano subjetivo, para Flusser a tradução torna-se uma ferramenta de importante superação cultural. Retomando os poderes mágicos das palavras, fazendo-se valer do poético para além do acadêmico, Flusser incorrerá em análoga "blasfêmia" ao demonstrar em seu Língua e Realidade que as tão "sacramentadas" categorias kantianas de análise da realidade estavam diretamente condicionadas à visão de mundo imposta pelas condições sintático-semânticas da língua alemã. Um exemplo disso é apontado no tocante às categorias kantianas de quantidade. Enquanto no alemão distingue-se a unidade, a multiplicidade e a totalidade, na língua dos tchecos, por exemplo, distingue-se "a unidade, a dualidade, a multiplicidade até quatro (multiplicidade organizada), e a multiplicidade de mais de quatro (multiplicidade amorfa).” (1964/2010: 52).

Quer dizer, a filosofia que arrogantemente buscaria traduzir a realidade através de uma língua "purificada” é, ela mesma, criação condicionada pelos limites ficcionais impostos por determinada língua de determinado povo. Flusser, fotografado habitualmente utilizando um par de óculos sobre a testa e outro sobre os olhos, esse que também pensou as linguagens visuais de sua época e das ainda por vir, teria afirmado que "o intelecto dispõe de uma coleção de óculos, das diversas línguas" (id.: 52) para observar a realidade. Eis a necessidade de uma poética da tradução, portanto.

Ele fez da tradução a matéria prima e o modus operandi de uma proposta radical: o mundo e a realidade são fabricados pela linguagem e cada língua produz seu mundo próprio. Alguém que pôde experimentar na pele e na carne a incompreensão e a

\footnotetext{
${ }^{5}$ Worte Waren ursprünglich Zauber, und das Wort hat noch viel von seiner alten Zauberkraft bewahrt. Durch Worte kann ein Mensch den anderen selig machen oder zur Verzweiflung treiben, durch Worte überträgt der Lehrer sein Wissen auf die Schüler, durch Worte reißt der Redner die Versammlung der Zuhörer mit sich fort und bestimmt ihre Urteile und Entscheidungen. Worte rufen Affekte hervor und sind das allgemeine Mittel zur Beeinflussung der Menschen untereinander. Wir werden also die Verwendung der Worte in der Psychotherapie nicht geringschätzen und werden zufrieden sein, wenn wir Zuhörer der Worte sein können, die zwischen dem Analytiker und seinem Patienten gewechselt werden.
} 
Tavares, P. H. - Flusser com Freud

intolerância, tendo que se traduzir entre o alemão, o tcheco, o inglês, o português, o francês, bem como o hebraico dos antepassados e o grego e o latim dos filósofos, pôde também construir tão bela filosofia, poética ou ensaística. Eis aqui um ponto fundamental: uma obra, conforme sua tradução, caberá em diferentes estantes de uma biblioteca. Pensemos, por exemplo, no Tao te king, obra fundamental do saber oriental. Na passagem do chinês, língua aglutinante de escrita ideográfica, segundo as categorias utilizadas por Flusser, para uma língua indo-europeia ou hamito-semítica de escrita fonográfica, teremos sérias dificuldades em cadastrarmos tal tradução num setor de religião, de filosofia, ou mesmo de poesia.

Talvez por trazer tais ideias, o referido livro de Flusser foi na época tão elogiosamente resenhado pelo grande patrono dos Estudos da Tradução em nossas terras: o húngaro-brasileiro Paulo Rónai. Para ele: "se cada língua é um mundo diferente e, ao mesmo tempo, o mundo inteiro, o problema da tradução e do poliglotismo revestese de importância descomunal. Antes que uma conversão, a tradução é uma comparação; mais do que isso, uma ressurreição" (in FLUSSER 1963/2010: 15).

Primeiro por uma questão de necessidade, Flusser traduzia nas diversas línguas pelas quais transitou. Do português ao alemão, deste para o francês ou para o inglês e assim por diante. O tcheco talvez tivesse aí um papel menor, ainda que seja uma das línguas de contraponto fundamentais em suas teses. Para Rainer Guldin, autor de Vilém Flusser: Philosophieren zwischen den Sprachen (Vilém Flusser: Filosofar entre as línguas), da necessidade, a tradução se torna método para o autor em questão: "Flusser traduz e retraduz seus próprios textos para conferir sua verdade e sua coerência interna, e ainda para criticar seu próprio pensamento" (GULDIN 2005: 64).

Eis como teria descrito em carta a Mira Schendel tal necessidade tornada método:

Escrevia tudo primeiro em alemão "que é a língua que mais pulsa no meu centro". Traduzia depois para o português, "que é a língua que mais articula a realidade social na qual me tenho engajado. Depois traduzia para o inglês, "que é a língua que mais articula a nossa situação histórica e que dispõe de maior riqueza de repertório e forma". Finalmente traduzia para a língua na qual queria que o escrito fosse publicado - "por exemplo, retraduzo para o alemão, ou tento traduzir para o francês, ou reescrevo em inglês. Procurava "penetrar as estruturas das várias línguas até um núcleo muito geral e despersonalizado para poder, com tal núcleo pobre, articular a minha liberdade". (apud BERNARDO in FLUSSER 1964/2010: 10). 
Tavares, P. H. - Flusser com Freud

No manuscrito inédito Retradução enquanto método de trabalho, num testemunho muito subjetivo, Flusser mostra como o contato singular e afetivo que tinha com cada uma das línguas gerava nele este ponto de vista múltiplo e caleidoscópico. Eis como o ensaísta trata os "espíritos”, como chamava, das línguas que nele pulsavam:

O alemão desfiava a sua mente a não se entregar ao convite sedutor da profundidade para, então, buscar clareza. $O$ francês, ao contrário, desafiava-o a resistir ao virtuosismo verbal para obrigar a língua a tocar em surdina. O português seria para ele a língua das digressões, logo, da indisciplina, convidando-o a conter-se. O inglês, língua síntese, contendo tanta ciência, técnica, filosofia e kitsch quanto nenhuma outra, desafiava-o a podar a profundidade alemã, o brilho francês e a genialidade portuguesa, de modo a reduzir o texto ao essencial. (apud BERNARDO in FLUSSER 1964/2010: 11)

A retradução seria para ele uma ars moriendi, um necessário e difícil jogo de despersonalização de alienação de um Eu ficcionalmente construído pelas faculdades de determinada língua, de determinada cultura específica. Seria um desafio ao confronto com o subjetivo e uma ultrapassagem da alienação egoica a que uma língua submete o falante para um feito que expande as possibilidades do Outro, do coletivo. Como aponta Guldin, a partir das reflexões de nosso autor "Todo traduzir é assim não somente uma exteriorização visível de um espaço subjetivo não mais visualizável, mas é também um ato criativo" (2005: 141, tradução nossa).

Freud, por sua vez, na já referida Traumdeutung, comparava o ofício de um psicanalista ao de um tradutor na análise dos sonhos.

Pensamentos do sonho e o conteúdo do sonho nos são dados como duas apresentações do mesmo conteúdo em duas línguas diferentes, ou melhor, o conteúdo do sonho aparece como uma transposição dos pensamentos de sonho em um outro modo de expressão, cujos caracteres e leis sintáticas podemos conhecer através da comparação do original com a tradução ${ }^{6}$ (FREUD 1900: 283 grifos nossos).

Essa decifração, comparável à de Champollion com os hieróglifos na pedra Roseta é um jogo de transposição de imagens. Uma transposição sempre fragmentária e que visa suplantar as inevitáveis ausências. Pela Psicanálise aprendemos também o quanto o eu é fruto de um autoengano promovido e construído pela linguagem. Freud com isso mostra

\footnotetext{
6 "Traumgedanken und Trauminhalt liegen vor uns wie zwei Darstellungen desselben Inhaltes in zwei verschiedenen Sprachen, oder besser gesagt, der Trauminhlat erscheint uns als eine Übertragung der Traumgedanken in eine andere Ausdrucksweise, deren Zeichen und Fügungsgesetze wir durch die Vergleichung von Original und übersetzung kennen lernen können."
}

Pandaemonium, São Paulo, v. 17, n. 23, Jun. /2014, p. 223-239 
Tavares, P. H. - Flusser com Freud

o quanto toda língua nos é sempre estrangeira (FREUD 1919) e sempre gerará em cada sujeito uma variante muito singular. Aliás, desde seus esboços teóricos surgidos na correspondência com Fliess, na célebre "carta 52", Freud teria construído a ideia dos sistemas psíquicos e a passagem de uma informação de um sistema a outro como uma tradução/transposição (Übersetzung), sendo o recalque (Verdrängung) um processo que geraria uma transcrição/transliteração (Umschrift) para outra linguagem: “A falha da tradução é isto o que clinicamente se chama de "recalque" (Die Versagung der Übersetzung, das ist das, was klinisch “Verdrängung” heißt) (FREUD 1896).

Para Freud a língua é não somente condição de nos inserirmos na cultura, mas também de a cultura se "inocular" de tal forma no sujeito, que ele passaria então a se confundir com o "gérmen" que porta e transmite. Não à toa as questões envolvendo a tradução da obra de Freud até hoje geram tanta discussão. Se Freud traduziu de forma tão magnífica e clara suas ideias no alemão, até hoje procuramos uma forma adequada de vertê-las ao português. Com a entrada de seus escritos para o domínio público em 2010, vemos surgir atualmente uma série de versões novas. Temos versões consideradas mais literárias, outras mais filosóficas, outras médico-cientificistas. Seu pensamento, afinal, borra as "fronteiras" entre Medicina, Literatura, Estudos Culturais, Psicologia etc. "Fronteira”, aliás, como lembra Flusser em Zwiegespräche (1990: 97) através do frontière francês, era um termo militar (front d'armée) que jamais deveria se aplicar à intelectualidade.

Para Freud, o desencontro é um ponto central em suas análises. Certa dose de desconforto e desencontro do sujeito na cultura é sempre inevitável. Seu mais célebre, lido e comentado ensaio chama-se, aliás: Das Unbehagen in der Kultur (O mal-estar na cultura) e nele encontram-se muitas das teses aludidas nesta exposição. É ali onde seu autor expõe que, em nome de um bem coletivo, abrimos mão da realização direta de nossos desejos individuais: "Descobriu-se que o ser humano se torna neurótico, pois não consegue suportar o grau de frustração que a sociedade lhe impõe a serviço dos ideais culturais"7 (FREUD 1930a: 218).

Estabelecer o equilíbrio entre os impulsos perversos de cada um e as demandas neurotizantes da cultura é o desafio que se impõe a cada sujeito. A comunicação é

\footnotetext{
7 "Man fand, dass der Mensch neurotisch wird, weil er das Mass von Versagung nicht ertragen kann, das ihm die Gesellschaft im Dienste ihrer kulturellen Ideale auferlegt..."
}

Pandaemonium, São Paulo, v. 17, n. 23, Jun. /2014, p. 223-239 
Tavares, P. H. - Flusser com Freud

sempre faltante e ruidosa, o que não nos desresponsabiliza de compreender tais limites e abdicarmos da onipotência por um lado, e de implicarmo-nos, por outro lado, nas possíveis brechas de realização que a existência em sociedade nos proporciona.

Para nossos dois pensadores dos efeitos da cultura no sujeito através do que a transmite, a língua, esta última operaria como aquilo que Wolfgang Lukas denomina de um Subjektinterne Fremde (estranho/estrangeiro interior/inerente ao sujeito). Muito das especulações freudianas sobre o Unheimliche (a inquietante estranheza) tem a ver com este estranho/estrangeiro que nos habita e nos faz pertencer a esta ou aquela cultura. Talvez o mais contundente exemplo da abordagem da relação psíquica entre o eu e a cultura se dê através do seu ensaio sobre este termo de difícil tradução, mas que porta em sua composição a negação (prefixo un-) da palavra Heim (lar) ou, por forçosa extensão, da Heimat, a pátria no sentido afetivo, que se oporia a Vaterland, pátria no sentido mais marcial ou cívico.

Como víamos ao início desta exposição, o vocabulário freudiano é perpassado pela ideia do atravessamento das fronteiras, do desalojamento, da imposição de forças persecutórias e ameaçadoras. Basta atentarmos também para a sua descrição da função libidinal e o par de conceitos de origem latina Fixierung - Regression como interessantes metáforas de uma vivência das diásporas "subjetivas", pelo nãopertencimento a um lugar. Nas Conferências para a Introdução à Psicanálise, mais especificamente na $22^{\mathrm{a}}$, Freud compara a função libidinal a um povo que "deixa seu território" (sein Wohnsitz verlässt), um grupo de migrantes (Vebände der Wanderer) (1916: 351). Eis a analogia da interdependência entre estes dois conceitos quase topográficos, como nos são apresentadas a regressão e a fixação:

Considerem que, se um povo em migração deixou atrás de si fortes destacamentos nos locais de parada de seu deslocamento, é provável que os escalões mais avançados tenderão a se retirar para esses locais de parada quando forem derrotados ou quando se defrontarem com um inimigo superior. Mas, também estarão em maior perigo de serem derrotados, quanto maior for o número deles, que ficou para trás na migração ${ }^{8}(1916$ : $353)$.

\footnotetext{
8 "Denken Sie daran, wenn ein Volk in Bewegung starker Abteilungen na den Stationen seiner Wanderung zurückgelassen hat, so wird es den weiter Vorgerückten naheliegen, sich bis zu diesen Stationen zurückzuziehen, wenn sie geschlagen werdenoder auf einen überstarken Feind stoßen. Sie werden aber auch um so eher ind die Gefaher der Niederlage kommen, je mehr sie von ihrer Anzahl auf der Wanderung zurückgelassen haben."
}

Pandaemonium, São Paulo, v. 17, n. 23, Jun. /2014, p. 223-239 
Tavares, P. H. - Flusser com Freud

Se a relação com o aspecto do nomadismo forçado de um povo é aqui tão evidente, no uso de tais termos latinos, causa certo espanto o quanto até hoje os tradutores de Freud não perceberam que outro conceito relacionado à sua teoria da libido se insere neste mesmo contexto. Se sua Besetzung foi muito inadequadamente traduzida para o inglês pelo neologismo de étimo grego cathexis ( $\kappa \alpha ́ \theta \varepsilon \xi 1 \varsigma$ ), derivando para catexia no português, os tradutores para as outras línguas europeias modernas são quase unânimes em apresentar derivados do latim investire (investimento, investiment, investissement, investidura) como alternativa. Entretanto, qualquer pessoa que consulte um dicionário alemão-português encontrará ali o sentido militar de "ocupação/assentamento".

A libido, portanto, cruzaria as "fronteiras" entre o doméstico $(\mathrm{Eu})$ e o estrangeiro (Objeto) para ali estabelecer seus assentamentos. É curioso o paralelo com o que teria apontado Flusser em relação ao binômio nomadismo $\mathrm{X}$ sedentarismo. Oficialmente tcheco-brasileiro, mas apátrida em seu exercício intelectual, Flusser fez a apologia do nomadismo e o fez através da sabedoria da língua alemã. Como nos coloca, "enquanto o homem se desloca (fahren), ele ganha experiência, conhece (erfahren). No momento em que ele se assenta (sitzen), sobrevem o efeito de tomar posse (besitzen) e tudo se complicaria." (apud BAITELLO JR.: 24).

A língua alemã, língua fundamental de expressão para Freud, cujo uso majestoso rendeu-lhe a homenagem do Prêmio Goethe em 1930, era também a que em Flusser mais fortemente pulsava e a que mais gerou seus importantes insights intelectuais. Ironicamente, foi aquela que acabou se revelando a língua nacional de um povo que a guerra fez seu suposto adversário. Judeus e alemães, afinal, diferentemente do nosso tão internalizado jus solis brasileiro, que faz alguém ser "filho das suas terras", têm seu pertencimento nacional muito mais marcado pela língua ou pela religião do que pela terra. Como nos aponta Bernardo, Vilém Flusser, “esse judeu sem Deus, à semelhança de Freud, é religioso a seu modo. No sentido radical e não paternal do termo, a língua é a sua dimensão religiosa, se implica o mistério por onde ele também se perde" (in FLUSSER 1964/2010: 12).

A língua alemã, porém, não era tão naturalmente sua. Como teria dito: "Minha cultura alemã persistiu, mas ganhou uma nova coloração: aquele que morava dentro do núcleo de mim mesmo foi o meu inimigo.” (apud FINGER 2008: 38). Talvez por isso tivesse chegado à conclusão: “encontro-me a mim mesmo como um problema de 
Tavares, P. H. - Flusser com Freud

tradução, isto é, como uma multiplicidade de sistemas a serem traduzidos entre si para um meta-sistema." (id.).

$\mathrm{O}$ intelectual que dada a sua origem judaica entendia que vivemos enquanto somos lembrados e que escrevemos, portanto, para não morrermos, teve em sua lápide inscrições em hebraico, tcheco e português, mas não da língua que mais fortemente falou em seu pensar. Ao final da vida, porém, teria se reaproximado dessa língua e de sua cultura, mas não mais com uma ilusão de "pertencimento". Como expõe em The Freedom of the Migrant:

Fui criado na cultura alemã e com ela me reencontro ao longo dos últimos anos. Em resumo, encontro-me hoje sem pátria porque muitas pátrias moram comigo. Isso manifesta-se diariamente no meu trabalho. Sinto-me em casa em pelo menos quatro línguas, e sinto-me desafiado e mesmo obrigado a traduzir e então retraduzir tudo que escrevo. (apud FINGER 2008: 47)

Daí talvez entendamos a sua defesa da Bodenlosigkeit (apatriedade / falta de chão) como saída ao constante alienamento nacionalista e ao limitado escopo do monolinguismo, já que para Flusser esta seria uma perigosa condição de alienação. $O$ monoglota pensaria que "Aquele que não fala a 'língua da gente', ou fala mais de uma língua é suspeito. Com razão, pois perdeu o fundamento firme da realidade que é justamente a "língua da gente". (id.: 59).

Para Freud a tradução fundamental era aquela a ser operada entre os sistemas subjetivos, entre o $E u$ e o Isso, o inconsciente e o consciente, as demandas superegoicas e o imperativo do desejo, para que o sujeito assumisse sua hybris, derrubando as fortificações fronteiriças que impedem o acesso às realizações possíveis, sem ter que incorrer na barbárie da imposição ou imputação das frustrações próprias a outrem. Para o criador da Psicanálise o sujeito deveria conhecer as condições de trocas simbólicas da cultura sem se desligar das responsabilidades por se valer de sua singularidade.

Freud, que escreveu Psicologia das Massa e análise do eu (Massenpsychologie und Ich-Analyse) e Por que a guerra? (Warum Krieg?) em resposta a indagação de Albert Einstein, sabia do perigo do "narcisismo das pequenas diferenças", aquele que leva ao alheamento de um sujeito no "corpo" de uma massa militarizada, e adverte-nos quanto a tais perigos. Em seu ensaio escrito sobre o paradoxo da guerra, como algo tão primitivo em meio às sociedades culturalmente tão avançadas, Zeitgemässes über Krieg

Pandaemonium, São Paulo, v. 17, n. 23, Jun. /2014, p. 223-239 
Tavares, P. H. - Flusser com Freud

und Tod (Considerações atuais sobre guerra e morte), nos lembra que em línguas arcaicas não havia diferença entre estrangeiro (fremd) e inimigo (feindlich) (1908: 36).

Para Flusser a tradução era o meio de não se alienar em determinado narcisismo cego imposto pela ilusão da língua única e sua apreensão inequívoca da realidade; "língua naturalizada" no sujeito monolíngue como a única possibilidade de mediação do sujeito com a realidade e com o outro social. Para ele "toda tradução é um aniquilamento" [...]. O salto de língua a língua, atravessando o abismo do nada, cria no intelecto aquela sensação de irrealidade, tão aparentada à angústia existencial." (FLUSSER 1964: 58). Este "salto tradutório" (über-setzen) seria a condição libertadora não da civilização, mas da necessária relativização e libertação dos limites impostos pelo escopo limitado por "fronteiras" de determinada cultura estabelecidos por determinada língua.

Neste sentido, teria assumido em Bodenlos, sua autobiografia, a apologia de uma superação do sentimento patriótico:

Uma vez transcendida a própria cultura (isto é, na situação de falta de fundamento), a gente passa a pairar por cima de um conjunto complexo de várias culturas, e a gente se vê a si próprio assim pairando. Isto implica problemas de vária ordem. Por exemplo: a gente vê interpenetrações culturais, hierarquias culturais e abismos entre culturas, e a gente vê os vários dinamismos que fazem com que as culturas se interpenetrem, se distanciem e se entredevorem. Tal visão permite comparações entre culturas, mas exclui toda valoração, e portanto todo engajamento em determinada cultura. (id.: 66-7).

Aproveitemos, pois, o belo trocadilho proposto por Abraham Moles a partir do nome de Flusser proposto como título de uma compilação de artigos escritos em homenagem aos 70 anos do autor: Überflusser. Se “über Flusser" significaria simplesmente "sobre Flusser”, überflüssig (supérfluo) é o que trans-borda o que flui (Fluss: rio / fliessen: fluir) em excesso (über: super). Eis um bom modo de traduzir algo "em seu nome”. Em junção com o nome de Freud (significando este "alegria" na língua alemã), na ultrapassagem das fronteiras linguísticas estaria a felicidade, a eudaimonia, em se superar as restrições das línguas como limites etnocêntricos. Lembrando o verso de André Abujamra em sua canção: "As águas é que são felizes, não têm que ter visto pra entrar num país" (grifos nossos), que transbordem os rios (Flüsse) e confluam as águas dos pensamentos desses dois autores fundamentais, para além de qualquer forma de fronteira, nacional, linguística ou acadêmica. 
Tavares, P. H. - Flusser com Freud

\section{Referências bilbliográficas}

Altounian, Janine. L'écriture de Freud - Traversée traumatique et traduction. Paris: Presses Universitaires de France, 2003.

BAITELlo JUNIOR, Norval. O leitor número 69 ou o marco zero de um futuro Flusser. in FLUSSER, Vilém. Língua e Realidade. São Paulo: Annablume, 1963/2010.

Bernardo, Gustavo. O Pensamento como dúvida. in Bernardo, Gustavo; Finger, Anke \& GULDIN, Rainer. Vilém Flusser: Uma Introdução. São Paulo: Annablume, 2008.

Bernardo, Gustavo. Prefácio. in Flusser, Vilém. Língua e Realidade. São Paulo: Annablume, 1963/2010.

Finger, Anke. As Redes de Flusser. in BERnARdo, Gustavo; Finger, Anke \& GUldin, Rainer. Vilém Flusser: Uma Introdução. São Paulo: Annablume, 2008.

FINGER, Anke. Vilém Flusser e os estudos culturais. in BERNARDO, Gustavo; FINGER, Anke \& GULDIN, Rainer. Vilém Flusser: Uma Introdução. São Paulo: Annablume, 2008.

FLUSSER, Vilém. Bodenlos - Uma autobiografia filosófica. São Paulo: Annablume, 1992/2010. . Língua e Realidade. São Paulo: Annablume, 1963/2010.

. Pós-História - Vinte instantâneos e um modo de usar. São Paulo: Duas Cidades, 1983.

. Zwiegespräche. Interviews 1967-1991. Göttingen: Klaus Sander, 1990/1996.

FREUD, Sigmund. Gesammelte Werke - Chronologisch geordnet. Frankfurt am Main: Fischer Verlag, 1999: Brief an Wilhelm Fliess (1896); Das Unbehagen in der Kultur (1930a); Das Unheimliche (1919); Die Traumdeutung (1900); Selbstdarstellung (1930); Vorlesungen zur Einführungen in die Psychoanalyse (1917); Zeitgemässes über Krieg und Tod (1908).

GAY, Peter. Freud: Uma Vida para Nosso Tempo. Trad. De Luiz Meyer. São Paulo: Companhia das Letras, 1988 / 1999.

GULDIN, Rainer. Philosophieren zwischen den Sprachen - Vilém Flussers Werk. Munique: Wilhelm Fink Verlag, 2005.

- Tradução e escrita multilinguística. In. BERNARDO, Gustavo; FINGER, Anke \& GULDIN, Rainer. Vilém Flusser: Uma Introdução. São Paulo: Annablume, 2008.

IRMEN, Friedrich. Langenscheidts Taschenwörterbuch der portugiesischen und der deutschen Sprache. Berlim: Langenscheidt, 1988.

LUKAS, Wolfgang. Das Selbst und das Fremde - Epochale Lebenskrisen und ihre Lösungen im Werk Arthur Schnitzlers. Munique: Wilhelm Fink Verlag, 1996.

MARTins, Cláudia S. Vilém Flusser - A tradução na sociedade pós-histórica. São Paulo: Humanitas/FAPESP, 2011.

Recebido em: 08/08/2013

aceito em: 19/03/2014

Pandaemonium, São Paulo, v. 17, n. 23, Jun. /2014, p. 223-239 